\section{ÓBITOS EM ADOLESCENTES POR ACIDENTES COM MOTOCICLETA ENTRE OS ANOS DE 2013 A 2017 NO BRASIL}

\section{DEATHS IN ADOLESCENTS BY MOTORCYCLE ACCIDENTS BETWEEN 2013 AND 2017 IN BRAZIL}

Ana Paula Santos Coelho ${ }^{1}$ / Mayara Cardoso da Silva1," / Midiã Ferreira dos $\operatorname{Santos}^{1} /$ Paloma Carvalho Dias ${ }^{1} /$ Raysa Messias Barreto de Souza ${ }^{1 /}$ Ricardo Bruno Santos Ferreira ${ }^{1}$

\section{INTRODUÇÃO}

Os acidentes de trânsitos são considerados um problema de saúde pública, acarretando cerca de 1,35 milhão mortes a cada ano, gerando um custo de $3 \%$ do produto interno bruto, para a maioria dos países. A Organização Mundial de Saúde (OMS) ainda afirma que os países subdesenvolvidos possuem um percentual de $93 \%$ dos óbitos, em decorrência dos acidentes de trânsito. Dentre esses, o Brasil está entre os países que apresentam maior número de óbitos no mundo (BRASIL, 2019).

De acordo com estudo realizado por Moreira et al. (2018), foram internados 2.272.068 indivíduos vítimas por acidente de transporte terrestre entre os anos de 1998 a 2015. Além de 42.291 mortes, pela causa já citada, só em 2013 e que o principal veículo utilizado, pelas vítimas que vieram a óbito, foi à motocicleta correspondendo a um total de 12.040 (MALTA et al., 2016).

Ressalta-se ainda que os motociclistas apresentam mais risco a acidentes de trânsito, devido à falta de segurança da motocicleta. $\mathrm{O}$ acidente de trânsito pode ser considerado como incidente de um ou mais veículos em movimento, que esteja trafegando em uma via pública ou privada (BRASIL, 2019).

Assim, com vista a garantir um trânsito seguro, foi instituído no Brasil o Código de Trânsito Brasileiro (CTB), em 1997, em que o trânsito e a segurança dele, passaram a ser responsabilidade das entidades componentes do Sistema Nacional de Trânsito. Nesse contexto, em 2008 entrou em vigor a Lei $n^{\circ} 11.705 / 2008$, que trouxe mais rigor para as penalidades voltadas para a condução de veículos sob o uso de álcool, com o objetivo de diminuir os acidentes de trânsito (BRASIL, 1997; ABREU; SOUZA; MATHIAS, 2018).

\begin{abstract}
RESUMO
Objetivo: Descrever o perfil dos óbitos em adolescentes no Brasil entre os anos de 2014 a 2017. Materiais e Métodos: Trata-se de um estudo descritivo, transversal com base em dados secundários, obtidos através do Sistema de Informação sobre Mortalidade em adolescentes por acidentes com motocicleta, foram estudadas as variáveis sexo, faixa etária e raça/cor. Resultados: Evidenciou-se que entre os anos de 2013 a 2017 o perfil predominante dos adolescentes vítimas de acidente de trânsito com motocicleta foi do sexo masculino, registrados como pertencente raça/cor negra (pretos + pardos), na faixa etária de 15 os 19 anos idade. Conclusão: É necessária a realização de ações educativas sobre o trânsito, adequação nas sinalizações de trânsito e melhoria no transporte público.
\end{abstract}

Palavras-chave: Adolescentes. Mortalidade. Acidentes de Trânsito. Motocicleta.

\section{ABSTRACT}

Objective: To describe the profile of deaths among adolescents in Brazil between the years 2014 to 2017. Materials and Methods: This is a descriptive, cross-sectional study based on secondary data, obtained through the Information System on Mortality in adolescents from accidents with a motorcycle, the variables sex, age and race / color were studied. Results: It was evidenced that between the years 2013 to 2017 the predominant profile of adolescents victims of motorcycle traffic accidents was male, registered as belonging to race / black color (blacks + browns), in the age group of 15 to 19 years old. Conclusion: It is necessary to carry out educational actions on traffic, adequacy of traffic signs and improvement in public transport.

Keywords: Adolescents. Mortality. Traffic Accidents. Motorcycles.

Submetido em: 08 de nov. 2019

Aceito em: 14 de fev. 2020

${ }^{1}$ Universidade do Estado da Bahia - UNEB, Guanambi, Bahia - Brasil.

E-mail para correspondência: mayara.matt@hotmail.com 
Segundo a Organização Mundial de Saúde (OMS), dentre os grupos mais vulneráveis a acidentes de trânsito estão os adolescentes, sendo este agravo a principal causa de morte entre crianças, adolescentes e jovens de 5 a 29 anos de idade (BRASIL, 2019). Nessa perspectiva, estudo demonstra que no período de 1996 a 2015 36,1\% do total de pessoas que vieram a óbito por acidentes de trânsito, estavam na faixa etária dos 10 aos 29 anos de idade (MOREIRA et al., 2018).

Conforme Barros et al. (2018), a juventude e adolescência, apresentam atitudes próprias da faixa etária, a busca pela liberdade procura por novidades, ousadia e adrenalina levam-nos a apresentar comportamentos arriscados, que associado a falta de experiência faz crescer o risco de acidentes. Nesse contexto, é evidenciado que no trânsito há adolescentes na direção de motocicletas, sem habilitação e até mesmo após ingestão de álcool.

Utiliza-se nesse estudo o conceito da OMS acerca do período que compreende a adolescência, que abrange a faixa etária dos 10 aos 19 anos de idade. Trata-se de um período complexo, uma vez que se configura como uma transição da infância para vida adulta, onde todas as mudanças decorrentes desse período torna o adolescente mais vulnerável a alguns agravos à saúde (VALLE; MATTOS, 2011).

Nesse sentido, justifica-se a necessidade do estudo pela alta incidência de óbitos por acidentes de trânsito em adolescente (BRASIL, 2019). Além disso, há grande escassez de pesquisas voltadas para a mortalidade no trânsito desse público específico (JESUS et al., 2017). Nessa perspectiva o objetivo do estudo é descrever o perfil dos óbitos em adolescentes no Brasil entre os anos de 2014 a 2017.

\section{MATERIAIS E MÉTODOS}

Trata-se de um estudo descritivo, transversal com base em dados secundários, obtidos através do Sistema de Informação sobre Mortalidade (SIM), consolidado e disponibilizado pelo Departamento de Informática do Sistema Único de Saúde (DATASUS). Foram utilizados registros de casos de óbitos em motociclista traumatizado por acidente de transporte no Brasil entre os anos de 2013 a 2017, na faixa etária dos 10 aos 19 anos de idade.

As variáveis estudadas foram: sexo, faixa etária e raça/cor. Para análise dos dados, realizaram-se cálculos de frequência absoluta, relativa, com auxílio do Microsoft Office Excel 2010. Por se tratar de um estudo utilizando dados secundários e de domínio público, não foi necessária a submissão ao Comitê de Ética em Pesquisa.

\section{RESULTADOS E DISCUSSÃO}

Foram notificados 60.843 óbitos por acidentes com motociclistas no Brasil entre os anos de 2013 a 2017, desses cerca de $12,62 \%$ estavam na faixa etária da adolescência, dos 10 aos 19 anos de idade. Os dados ainda mostram que, dentre os anos estudados, 2014 foi o ano com mais registros de óbitos por acidentes com motociclista adolescentes no Brasil, totalizando 1.709 óbitos.

O uso da motocicleta é crescente no Brasil, de acordo com o DETRAN em 2010 a frota de motocicleta alcançava os 13.950.448, representando cerca de $21,5 \%$ do total de veículos. No mesmo sentido, vem se tornando mais frequente a mortalidade nos acidentes de trânsito com motocicleta, chegando a um crescimento de $875 \%$, de 1990 para 1996 (BARROS, 2018).
Os acidentes de trânsito, que incluem os acidentes com motocicleta, são considerados como causas externas evitáveis e não intencionais. Atingem pessoas de todas as idades e atualmente representam o principal problema de mortalidade em crianças e adolescentes (RIZZO et al., 2017).

Em seu estudo realizado sobre prevalência dos acidentes de motocicleta envolvendo os adolescentes, Barros et al. (2018) constatou que grande dos adolescentes entrevistados utilizavam a motocicleta para o trabalho. Dessa forma, fica implícito que os acidentes de trabalho e de trânsito são indissociáveis, sendo, inegável a responsabilidade das empresas para a prevenção de acidentes com motociclista, principalmente no público jovem (MOREIRA et al., 2018).

Nessa perspectiva, quando realizada a estratificação da faixa etária da adolescência, dos 10 a 14 anos e 15 a 19 anos de idade, nota-se que os adolescentes na faixa etária dos 15 aos 19 anos de idade, apresentavam percentual maior de óbitos em motociclistas. De acordo com os dados obtidos, $93,11 \%$ das notificações de morte em motociclistas adolescentes, pertenciam a essa faixa etária, como pode ser observado no gráfico 1. Dessa forma, é levantada a hipótese que os dados se justificam por esses adolescentes mais velhos, já estarem inseridos no mercado de trabalho.

Em relação ao sexo, em todos os anos do estudo, o sexo masculino prevalece com alto número de óbitos em adolescentes pela causa já citada. Os dados mostram um percentual 5 vezes maior, na taxa total de mortalidade no sexo masculino na população em estudo, correspondendo a $85,26 \%$, como mostra a tabela 1 . 
Gráfico 1 - Óbitos em motociclista traumatizado por acidente de transporte no Brasil entre os anos de 2013 a 2017, segundo a faixa etária da adolescência.

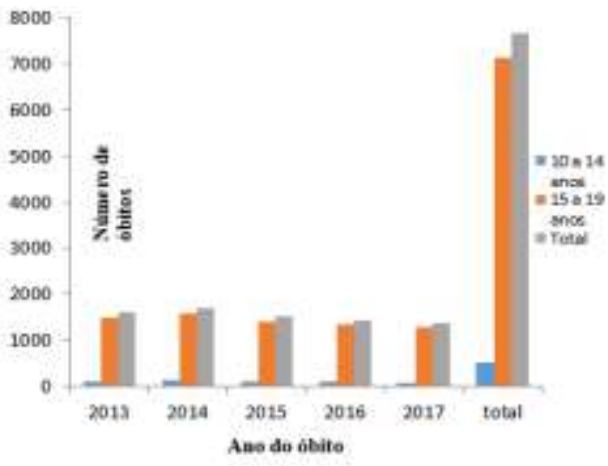

Fonte: DATASUS

Não obstante, estudo sobre os impactos do CBT e a lei seca nos acidentes de trânsito, corroboram com a alta mortalidade na população masculina, presentes neste estudo, e refere que $77 \%$ das vítimas de trânsito são homens. Pesquisas ressaltam que a predominância do sexo masculino nos acidentes com motocicleta dá-se em decorrência da cultura social, pois os homens são os que mais conduzem veículos, e dessa forma estão mais expostos aos riscos do trânsito (ABREU; SOUZA; MATHIAS, 2018; BARROS et al., 2018).

Quanto à raça/cor dos adolescentes que sofreram óbitos em decorrência de acidentes com motocicleta, $60,09 \%$ deles foram registrados como pertencentes à raça/cor negra (pretos + pardos) seguidos da raça/cor branca com $36,22 \%$ do total. Salienta-se que do total de registros quanto à raça/cor 241 são ignorados, tendo um percentual de $3,14 \%$.

Nesse contexto, o estudo de Malta et al. (2016), demonstra que os indivíduos de raça/cor branca faziam mais uso de equipamentos de proteção para conduzir e ser passageiro na motocicleta. Fazendo uma relação entre o estudo de Malta e a presente pesquisa, o número elevado de acidentes com

motociclista de raça/cor negra (preta + parda) pode ser em decorrência da falta de uso de equipamentos de proteção.

No entanto, a autoidentificação e a heteroclassificação da raça/cor pode interferir no estudo dessa variável. Há uma polaridade e uma subjetividade no processo classificatório, ademais o racismo e a cultura da população refletem em como a indivíduo se autoclassifica e como a sociedade o classifica (Brasil, 2013).

Tabela 1 - Óbitos em motociclista traumatizado em acidente de transporte no Brasil, na faixa etária de 10 a 19 anos de idade, entre os anos de 2013 a 2017, segundo raça/cor e sexo.

\begin{tabular}{|c|c|c|c|c|c|c|c|c|c|c|c|c|}
\hline & \multicolumn{2}{|c|}{2013} & \multicolumn{2}{|c|}{2014} & \multicolumn{2}{|c|}{2015} & \multicolumn{2}{|c|}{2016} & \multicolumn{2}{|c|}{2017} & \multicolumn{2}{|c|}{ TOTAL } \\
\hline & $\mathbf{n}$ & $\%$ & $\mathbf{n}$ & $\%$ & $\mathbf{n}$ & $\%$ & $\mathbf{n}$ & $\%$ & $\mathbf{n}$ & $\%$ & $\mathbf{n}$ & $\%$ \\
\hline \multicolumn{13}{|l|}{ Raça/cor } \\
\hline Branca & 600 & 36,99 & 639 & 37,39 & 577 & 37,96 & 457 & 31,63 & 509 & 36,78 & 2782 & 36,22 \\
\hline Preta & 59 & 3,64 & 84 & 4,92 & 62 & 4,08 & 75 & 5,19 & 58 & 4,19 & 338 & 4,4 \\
\hline Amarela & 1 & 0,06 & 4 & 0,23 & 4 & 0,26 & 3 & 0,21 & 2 & 0,14 & 14 & 0,18 \\
\hline Parda & 883 & 54,44 & 909 & 53,19 & 826 & 54,34 & 866 & 59,93 & 793 & 57,3 & 4277 & 55,69 \\
\hline Indígena & 5 & 0,31 & 7 & 0,41 & 7 & 0,46 & 6 & 0,42 & 3 & 0,22 & 28 & 0,36 \\
\hline Ignorado & 74 & 4,56 & 66 & 3,86 & 44 & 2,89 & 38 & 2,63 & 19 & 1,37 & 241 & 3,14 \\
\hline \multicolumn{13}{|l|}{ Sexo } \\
\hline Masc & 1363 & 84,03 & 1450 & 84,84 & 1308 & 86,05 & 1245 & 86,16 & 1182 & 85,4 & 6548 & 85,26 \\
\hline Fem & 259 & 15,97 & 259 & 15,16 & 212 & 13,95 & 200 & 13,84 & 202 & 14,6 & 1132 & 14,74 \\
\hline Total & 1622 & 100 & 1709 & 100 & 1520 & 100 & 1445 & 100 & 1384 & 100 & 7680 & 100 \\
\hline
\end{tabular}

\section{CONCLUSÃO}

Com a realização do estudo evidenciou-se que entre os anos de 2013 a 2017 o perfil predominante dos adolescentes vítimas de acidente de trânsito com motocicleta foi do sexo masculino, registrados como pertencente raça/cor negra (pretos + pardos), na faixa etária de 15 os 19 anos idade.

Ressalta-se como limitação do estudo, a falta de informação no DA-

TASUS sobre a posição do adolescente na motocicleta no ato do acidente. Isso impede o estudo de uma variável importante, já que de acordo com as leis brasileiras estão aptos a conduzir veículo apenas indivíduos maiores de 18 anos que estejam habilitados, assim sugere-se estudos sobre esta variável.

Quanto às ações, diante desse problema de saúde pública, é necessário que seja realizado programas com ações educativas sobre o trânsito, o uso dos equipamentos de proteção para toda população, bem como adequação nas sinalizações de trânsito.

\section{(1)}


leiro e da Lei Seca na mortalidade por acidentes de trânsito. Cadernos de Saúde Pública, [s.i], p.1-13, 2018. Disponível em: <https://www.scielosp.org/article/csp/2 018.v34n8/e00122117/\#>. Acesso em: 30 set. 2019.

BARROS, Francisco Hilângelo Vieira et al. Prevalência dos Acidentes de Motocicleta Envolvendo os Adolescentes de Quixadá. Id on Line Rev. Mult. Psic. [S.I], v.12, n. 42, p. 511524, 2018. Disponível em: <https://idonline.emnuvens.com.br/id/ article/view/1454>. Acesso em 03 Out. 2019.

BRASIL. José Luís Petruccelli. Instituto Brasileiro de Geografia e Estatística (Org.). Características Étnico-raciais da População: Classificações e Identidades. 2. ed. Rio de Janeiro, 2013. 208 p. Disponível em:

<https://biblioteca.ibge.gov.br/visualiz acao/livros/liv63405.pdf $>$. Acesso em: 16 set. 2019.

BRASIL. Lei $n^{\circ} 9.053$, de 23 de setembro de 1997. Institui O Código de Trânsito Brasileiro. Brasília, Disponível em:

<http://www.planalto.gov.br/ccivil_03/ LEIS/L9503.htm>. Acesso em: 30 set. 2019.

BRASIL. OMS/OPAS. . Folha informativa - Acidentes de trânsito. 2019.

Disponível em:

<https://www.paho.org/bra/index.php? op-

tion $=$ com_content $\&$ view $=$ article $\&$ id $=5$ 147:acidentes-de-transito-folhainformativa\&Itemid $=779>$. Acesso em: 30 set. 2019.

JESUS, Valdinei Ferreira de et al.. Causas associadas aos acidentes de trânsito envolvendo motociclistas: revisão integrativa. Revista de Enfermagem do Centro-oeste Mineiro, [s.i], v. 7, n. 1514, p.1-8, 2017.

MALTA, Deborah Carvalho et al.. Lesões no trânsito e uso de equipamento de proteção na população brasileira, segundo estudo de base popula- cional. Ciênc. saúde coletiva, Rio de Janeiro, v. 21, n. 2, p. 399-410, Fev. 2016. Disponível em: $<$ http://www.scielo.br/scielo.php?scrip $\mathrm{t}=$ sci_arttext\&pid=S141381232016000 $200399 \& \operatorname{lng}=$ en\&nrm=iso>. Acesso em: 03 Out. 2019.

MOREIRA, Marcelo Rasga et al.. Mortalidade por acidentes de transporte de trânsito em adolescentes e jovens, Brasil, 1996-2015: cumpriremos o ODS 3.6? Ciênc. saúde coletiva, Rio de Janeiro, v. 23, n. 9, p. 27852796, Set. 2018. Disponível em: <http://www.scielo.br/scielo.php?scrip $\mathrm{t}=$ sci_arttext\&pid=S141381232018000 $902785 \& \operatorname{lng}=$ en\&nrm=iso $>$. Acesso em 03 Out. 2019.

RIZZO, Thiago Sant Anna et al.. Perfil epidemiológico dos acidentes de trânsito entre crianças e adolescentes. Arq. Catarin Med., [S.I], v. 46, n. 4, p. 91102, 2017. Disponível em: < http://www.acm.org.br/acm/seer/index. php/arquivos/article/view/213/208>. Acesso em 03 Out. 2019.

VALLE, Luiza Elena L. Ribeiro do; MATTOS, Maria José Viana Marinho de. Adolescência: as contradições da idade. Rev. Psicopedagogia, Belo Horizonte, v. 87, n. 28, p.321-323, 2011. Disponível em:

<http://pepsic.bvsalud.org/pdf/psicope d/v28n87/12.pdf $>$. Acesso em: 12 ago. 2019. 